\title{
Establishment automatically contour blasting passport for tunnel in AutoCAD by VOLVN 3.0 software
}

\author{
Minh Nguyen $\mathrm{Ngoc}^{1,2, *}$, Ping Cao ${ }^{1}$, and Duc Thang Pham ${ }^{2}$ \\ ${ }^{1}$ School of Resources and Safety Engineering, Central South University, Changsha, Hunan, China \\ ${ }^{2}$ Quang Ninh University of Industry, Quang Ninh, Vietnam
}

\begin{abstract}
The smooth blasting method has been researched, developed and strongly applied for long-term underground construction, such as principal mining excavations, tunnels and hydroelectric projects... with the main purpose of minimizing the explosion impact on rock and creating a well-shaped boundary. In this research, a software was developed to establish automatically the tunnel contour blasting passport in AutoCAD. Using the software in each blast design model, it is quickly possible to determine number of blastholes, specific charge, specific drilling and drawing automatically of blasting passport in AutoCAD. The interaction between the software and AutoCAD is a new and important factor that helps to complete an automatically closed cycle on computer from introducing parameters to designing blasting passport in AutoCAD, thereby contributing to increase efficiency of production and minimize risks in blasting works.
\end{abstract}

\section{Introduction}

Drilling and blasting is a preferred method of rock excavation worldwide due to low initial investment, cheap explosive energy, easy acceptability among the blasting engineers and possibility to deal with different shapes and sizes of openings [1]. The smooth blasting method has been widely used in the construction of mountain tunnels to decrease the volume of overbreak or underbreak and maintain the tunnel outline in the design shape [2]. One of the most important factors influencing on tunnel blast efficiency is the proper design of blasting pattern [3]. Along with the development of information technology, the blasting passports in our country are often designed in AutoCAD environment.

In our country, the designing of blasting passport methods are manual method (interpolation new passport from the old available sample passport in AutoCAD) or semimanual method (firstly calculating the blasting parameters by Excel table and then proceeding to draw it in AutoCAD). The manual or semi-manual methods are not accurate, can commit errors and take a lot of time because the designer has to manipulate with a huge amount of information. Since then, to optimize this process, the creating of blasting software is an important domestic and foreign research topic to serve blasting works and

* Corresponding author: minhnguyen1986vn@csu.edu.cn 
avoid risks that may be caused by an error during the calculating or drawing blasting passport process.

Some commercial software such as JKSimBlast, I-Blast Pro... are not usable in our country because they are not capable of setting up automatically a blasting passport in AutoCAD to synchronize with the existing database. Among numerous domestic studies, creating a suitable software to the Vietnamese practical conditions is an urgent need. However, until the day none of software is capable of drawing automatically of blasting passports in AutoCAD.

Grasping the requirements of the connection between smooth blasting method and AutoCAD in order to free engineer operations and creating a high accuracy in the work of setting up a blasting passport, the authors have researched and developed VOLVN 3.0 software. The interactive features and algorithms linking between Delphi programming language and AutoCAD were published for the first time according to the authors' opinion.

\section{Software construction method}

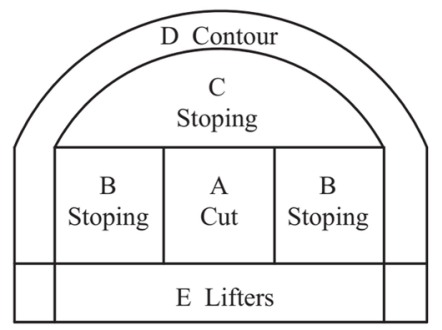

Fig. 1. Tunnel sections [3]

VOLVN 3.0 was designed based on dividing tunnel face into five sections in accordance with Langefors's primary idea as seen in Figure 1. These sections include cut, stoping sections, contour and lifters [3].
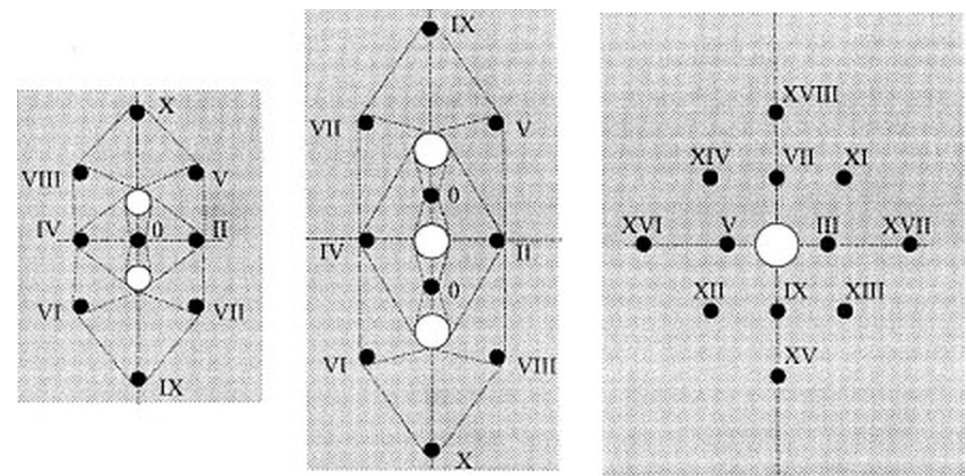

Fig. 2. Three standard parallel drillhole cut methods proposed by NTNU [4]

According to the combination of three standard parallel drillhole cut methods proposed by NTNU model are shown in Figure 2 [4] and practical researches, the software provides four parallel drillhole cut methods are shown in Figure 3. The parallel drillhole cut method is selected depending on the drilling machine type, the face advance for one cycle and the face area. The distance between parallel drillholes is automatically calculated by the relation between the empty drillhole diameter and the strength of the rock. The first cutting method is used for small tunnel section, manual drilling machine and the face advance for 
one cycle no more than $2,8(\mathrm{~m})$. The second cutting method is used for tunnel of small to medium section, one arm types of jumbo drilling machine and the face advance no more than $4,0(\mathrm{~m})$. The third and fourth cutting method is used for large section, double-arm types of jumbo drilling machine and the face advance can get up to $6,0(\mathrm{~m})$.

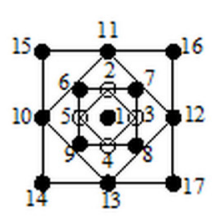

(1)

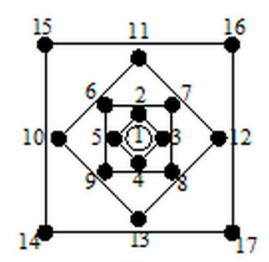

(2)

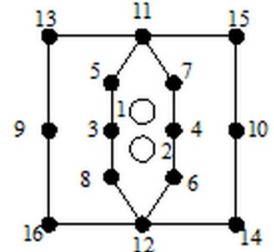

(3)

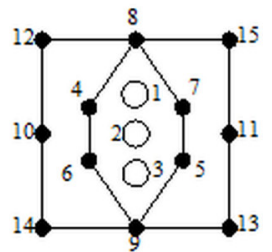

(4)

Fig. 3. Four parallel drillhole cut methods proposed by VOLVN 3.0 software

\subsection{Software block diagram}

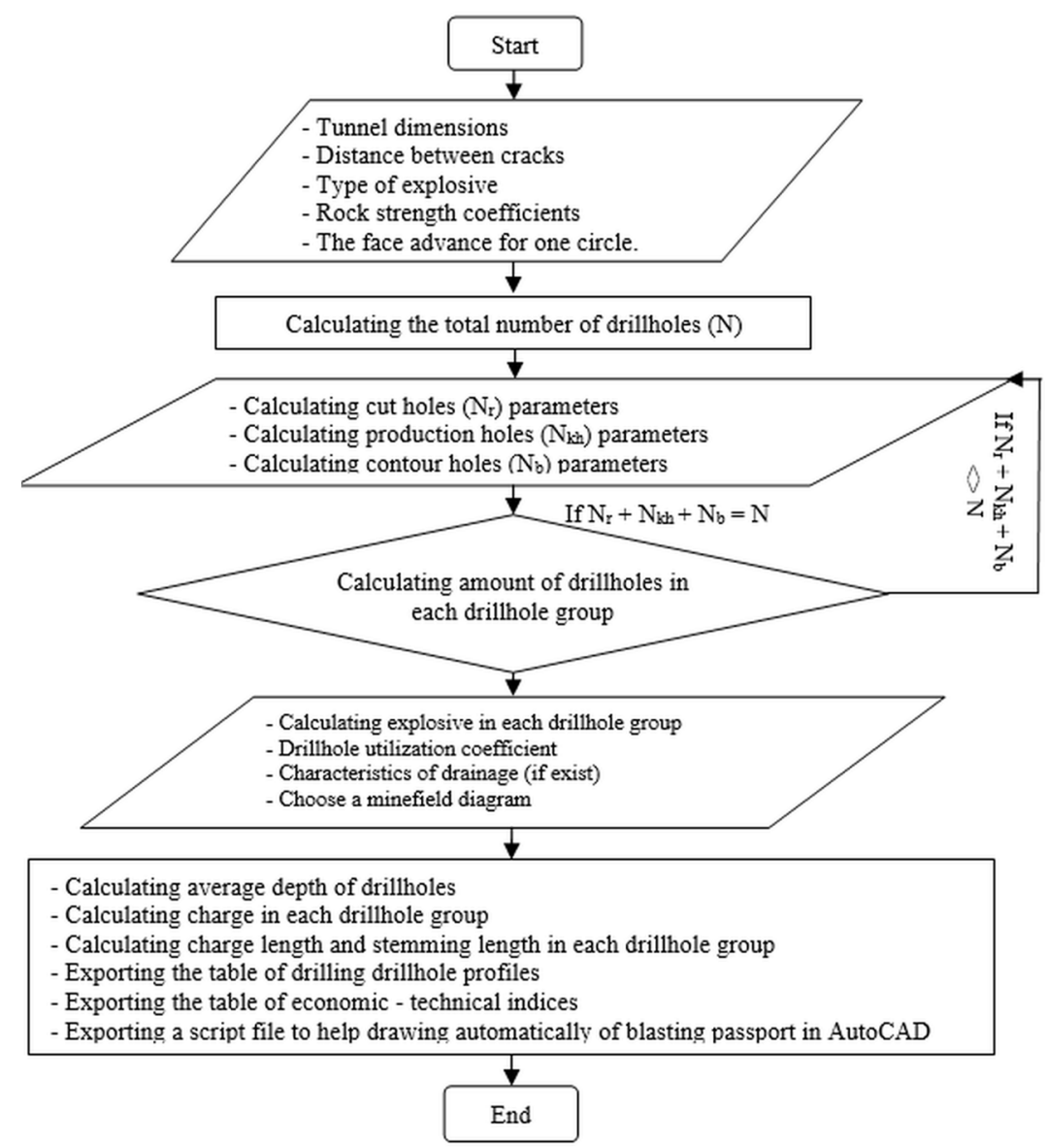

Fig. 4. Software block diagram

The input data includes of tunnel dimensions, distance between cracks in the face, type of explosive, rock strength coefficients and the face advance distance for one circle. They are logically described in calculation formulas and programming codes in Delphi object- 
oriented programming language to create VOLVN 3.0 blasting software. The block diagram of calculation steps for programming the software is shown in Figure 4.

\subsection{Automatically drawing in AutoCAD methods}

There are many different methods to draw automatically in AutoCAD such as:

- Creating script file

- Creating DFX text file

- Programming directly in AutoCAD environments by using AutoCad programming languages such as Lisp or Object ARX or VBA.

Among those methods, creating script file is selected because it is a simple programming method and close to the manual drawing method. So, VOLVN software was created by having an exported script file application. For example, to draw a semi-circular tunnel with a height of $\mathrm{h}(\mathrm{m})$ and a width of B (m), VOLVN 3.0 software must create a Script file with the following contents: pline 0, h@0,-h@B, $0 @ 0, \mathrm{~h} \operatorname{arc} \mathrm{S}$ B / 2, (h + B / 2) $0, \mathrm{~h}$.

Thus, VOLVN 3.0 software is the result of the combination of specialized knowledge, Delphi object-oriented programming language and AutoCAD drawing using script file method.

\section{Research result}

In order to establish automatically a contour blasting passport for tunnel in AutoCAD, a software is called VOLVN 3.0 that was programmed by Delphi object-oriented programming language. The software consists of 8000 code lines and is able to run directly in Windows 7 without installation.

To understand more specific about software working procedure, the following example is one of blasting passports was created during the construction of hydropower project: Establishing a blasting passport for a semi-circular hydroelectric tunnel with rock strength index according to Protodyakonov $\mathrm{f}=8$ [5], height of $6.5 \mathrm{~m}$, width of $6.2 \mathrm{~m}$. The rock in the face is homogeneous. The distance between the cracks on the face is $0.7 \mathrm{~m}$. The explosive used is P113 with following characters: lead bomb expansion $320 \div 330 \mathrm{ml}$, explosive speed $4200 \div 4500 \mathrm{~m} / \mathrm{s}$ and the specific gravity $1100 \div 1250 \mathrm{~kg} / \mathrm{m} 3$. The face advance of one tunneling cycle is $3.0 \mathrm{~m}$.

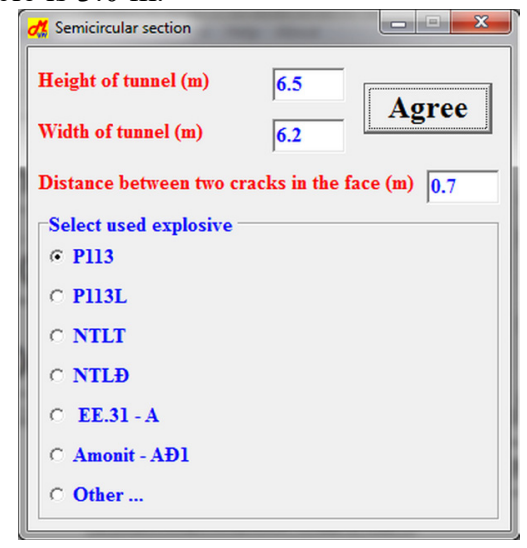

Fig. 2. Introducing initial data 
In the first window of the application, enter initial parameter values such as tunnel height of $6.5 \mathrm{~m}$, width of $6.2 \mathrm{~m}$ and distance between cracks on the face $0.7 \mathrm{~m}$ and choose the type of explosive is P113 as shown in Figure 5.

Fig. 6. Table of drillhole profiles

In the next windows, the software will automatically calculate and update the data. The results are the table of drilling blastholes profiles as shown in Figure 6 and the table of economic - technical indices as shown in Figure 7. Both tables can be saved as an Excel table file or printed directly.

\begin{tabular}{|c|c|c|c|c|c|c|}
\hline \multicolumn{6}{|c|}{ do Semicircular section } & \begin{tabular}{|l|l|l|}
0 & 0 & $x$ \\
\end{tabular} \\
\hline \multirow{2}{*}{\multicolumn{7}{|c|}{$\begin{array}{l}\text { Save } \underline{\text { Print }} \\
\text { Drilling hole profiles }\end{array}$}} \\
\hline & & & & & & \\
\hline Hole number & Amount of holes & Hole length $(\mathrm{m})$ & Tharge per hole $(\mathrm{kg}$ & Charge length $(\mathrm{m})$ & Stemming length $(\mathrm{m})$ & Horizontal inclir \\
\hline $1 \div 17$ & 17 & 3.6 & 1.5 & 1.5 & 2.1 & \\
\hline $18-76$ & 59 & 3.35 & 1.5 & 1.5 & 1.85 & \\
\hline $78 \div 86$ & 9 & 3.35 & 1.5 & 1.5 & 1.85 & \\
\hline \begin{tabular}{|l|}
77,87 \\
|
\end{tabular} & 2 & 3.35 & 1.5 & 1.5 & 1.85 & \\
\hline $88 \div 95$ & 8 & 3.35 & 1.35 & 1.35 & 2 & \\
\hline $96 \div 102,104 \div$ & 14 & 3.35 & 1.35 & 1.35 & 2 & \\
\hline 103 & 1 & 3.35 & 1.35 & 1.35 & 2 & \\
\hline Sum & 110 & 372.75 & 155.7 & 159.9 & 212.85 & \\
\hline \multicolumn{7}{|l|}{$1 \cdot \square$} \\
\hline & & & Agree & Back & & \\
\hline
\end{tabular}

Fig. 3. Table of economic - technical indices

In the next windows, the software will automatically calculate and update the data. The results are the table of drilling blastholes profiles as shown in Figure 6 and the table of economic - technical indices as shown in Figure 7. Both tables can be saved as an Excel table file or printed directly.

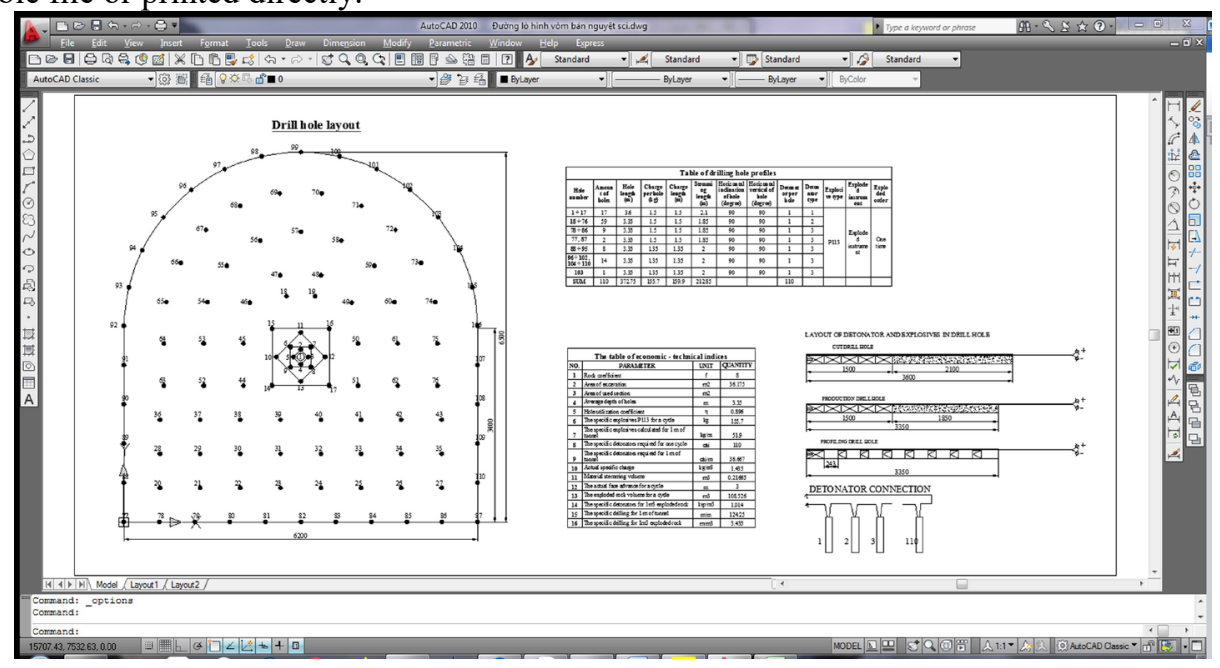

Fig. 4. Blasting passports in the AutoCAD

According to the main purpose of research, the VOLVN 3.0 software provides a script file that can be used to draw automatically blasting passports in the AutoCAD environment as shown in Figure 8. This obtained blasting passport is the result of the calculation process from the initial data. 
The evaluation of the research results was checked by using software in the construction of Dak My 3 hydropower project that is constructed by One Member Limited Song Da 10.1 Company. The application of the software has produced good results, with the time of designing blasting passport reducing from 3 hours to 3 minutes, the drillhole utilization coefficient up to $95 \%$, the tunnel boundary was created very well and satisfied all of the investor requirements.

\section{Conclusion}

The tunneling project in our country is growing and expanding. This requires reducing manual labor, quickly solving blasting design operations and synchronizing databases by using computers. Since then, VOLVN 3.0 software has been successfully built to help in completing an automated closed cycle from calculating parameters to designing of blasting passport in AutoCAD. The interactive features and algorithms linking between Delphi programming language and AutoCAD were published for the first time. The software solves satisfactorily the Vietnamese practical condition requirements when it is the result of the combination of specialized knowledge, Delphi object-oriented programming language and AutoCAD drawing using script file method.The VOLVN 3.0 software ensures quickly, conveniently, accurately and automatically to create a tunnel smooth blasting passport in AutoCADand contributes to increasing efficiency, reducing risks in blasting operations.

\section{References}

1. H. K. Verma, N. K. Samadhiya, M. Singh, R. K. Goel, P. K. Singh, Tunn. Undergr. Sp. Technol., 71, 149 (2018)

2. K. Liu, B. Liu, Tunn. Undergr. Sp. Technol., 70, 363 (2017)

3. K. Soroush, Y. Mehdi, E. Arash, Int. J. Min. Sci. Technol., 25, 595 (2015)

4. S. Zare, A. Bruland, Tunn. Undergr. Sp. Technol., 21, 533 (2006)

5. M. Protodyakonov, Mechanical properties and drillabilityof rocks, Proc. fifth Symp. rock Mech., 103 (1962) 